\title{
¿EL MUNDO NECESITA DE
JESÚS? LA VERDADERA
MISIÓN DEL CRISTIANO
}

Rojas Yauri, Benjamín Universidad Peruana Unión benjamin@upeu.edu.pe

Fecha de recepción: Enero 2013 Fecha de aceptación y versión final: Mayo 2013

\section{Resumen}

Este estudio aborda un tema polémico, actual y complejo, directamente relacionado con el quehacer misionero del cristianismo. El surgimiento de la teología de la liberación y la teología social influyó de forma significativa en la comprensión que el cristianismo tiene respecto de su misión, de la del Señor Jesús y de la razón por la cual el mundo necesita de Él. En la primera parte de este artículo, el autor discute la pregunta iel mundo necesita de Jesús? En la segunda parte, se presenta las razones bíblicas por las cuales el mundo necesita del Señor Jesús, y a través de la primera y segunda parte se exponen las implicancias, que tiene la pregunta planteada y su respuesta, sobre el cumplimiento de la misión por parte del verdadero cristianismo.

Palabras clave: Misión, evangelismo, necesidad de Jesús, fin del pecado. 
The study addresses a controversial, current and complex issue, directly related to the missionary work of the Christian. The emergence of Liberation Theology, and Social Theology, significantly influenced the understanding christianity has about their mission, the mission of the Lord, and the reason the world needs Him. In the first part of this article, the author discusses the question, Does the world need Jesus? The second part presents the biblical reasons why the world needs Jesus, and through the first and second part, the article outlines the implications that the question and its answer have on the fulfilment of the mission by the true Christianity.

Keywords: Mission, evangelism, The need of Jesus, end of $\sin$ 


\section{Introducción}

"Jesús es todo", "Cristo es la Solución" y "La esperanza es Jesús", son algunos de los más populares lemas que presentan como la mayor necesidad del mundo al Señor Jesús. Esto demuestra que el ser humano tiene inseguridad sobre el futuro y que no está plenamente realizado. Que aunque existen unos pocos optimistas, la realidad es que aun Freud, a quien debemos la universalidad de la neurosis y sus colegas de la escuela de Frankfurt quienes popularizaron en los sesenta la frase 'el mundo está al revés', ${ }^{1}$ reconocen junto a una gran cantidad de seres humanos que el mundo está cada vez peor. ${ }^{2}$ Esta realidad

1 Naranjo afirma, que Freud propone la neurosis mundial y que los posfreudianos como Fromm, sus colegas de la escuela Frankfurt, R.D. Laing y el gremio de los psicólogos humanistas, serán los que comprendan más cabalmente esta realidad y los que harán famosa la frase 'el mundo está al revés.' Claudio Naranjo, Cambiar la educación para cambiar el mundo (Providencia, Chile: Editorial Cuarto Propio Indigo, 2007), 73.

2 Naranjo señala que "La conciencia de que 'el mundo está loco' se ha generalizado lo suficiente hoy en día como para que olvidemos que se trata de algo bastan- caótica mundial, ha generado una serie de propuestas, que intentan devolver al ser humano la esperanza de un mundo mejor, o mejor, el sueño utópico de que es posible construir un mundo perfecto, un paraíso, que para algunos existió y que para otros solo es un ideal ilusorio.

Los métodos propuestos para conseguir este ideal, así como las instituciones que los han propuesto, han sido diversos, ${ }^{3}$

te reciente". Ibíd. Samsam dice, "Últimamente, el mundo está cada vez peor y su ética y moral arrastrados y pisoteados en el fango de las calles". Elías Natanael Samsam Valipur, El cristianismo bíblico (Maitland, FL: Xulon Press, 2006), 75.

3 En el siglo XVIII surgió el iluminismo y con ella la era de la razón, se creyó que esta época daría solución a los más grandes flagelos humanos, sufridos aparentemente debido a la ignorancia y al abuso de la religión, sin embargo, no pasó mucho tiempo, para que la primera y la segunda guerra mundial, demuestren al mundo, que el uso de la razón no garantiza la construcción de la sociedad perfecta. Esto generó una desesperanza en los principales axiomas que gobernaron la edad moderna, creando así el escenario perfecto para el surgimiento del posmodernismo, que aunque todavía con algo de desconfianza sobre el futuro, al igual que sus predecesoras, cree ser la alternativa para que el ser humano alcance a vivir en su paraíso, su mundo perfecto. Véase, Clyde P. Greer, "Honestidad en el tratamiento de la histo- 
pero es el cristianismo, el que más fuertemente ha promovido la idea de un mundo perfecto, donde reine toda buena virtud, como la verdad, la justicia y el amor. Y aunque no todos deseen transformar este mundo en uno perfecto, hay quienes creen que la misión del cristianismo es intervenir en todos los escenarios mundiales para lograr este objetivo. Debido a ello, el cristianismo en general afirma que el mundo necesita de Jesús. Sin embargo, es de suma importancia conocer, qué significa esto.

\section{El mundo necesita de Jesús}

No existe un texto bíblico en el que se afirme que el mundo necesita de Jesús, sin embargo, basados en algunos textos bíblicos que pueden dar esta idea, los predicadores se han encargado de hacer de esta frase una especie de verso deuterocanónico. ${ }^{4}$

ria", en Piense conforme a la Biblia, ed. Richard Mayhue y John MacArthur (Grand Rapids, MI: Editorial Portavoz, 2005), 285.

4 Siendo que deuterocanónico es el término que se usa para referirse a los libros apócrifos, aquellos que hacen parte de la Septuaginta (LXX) y la Vulgata pero
En el mundo cristiano todos estarán de acuerdo con esta sentencia -el mundo necesita de Jesús-, pero donde el cristianismo no se ha puesto de acuerdo es en la interpretación de ella.

Fundamentándose en esta premisa, hay quienes han creado poemas y hermosos himnos que hablan de la importancia del Señor Jesús para el ser humano y para el mundo, uno de ellos es el compuesto por Will L. Thompson, dice,

Jesús es todo para mí bajo del cielo,

Él es mi fuerza y mi vigor día tras día,

Él es mi dicha, mi gozo, mi consuelo,

Y sin su ayuda y sin su amor yo caería.

que no están incluidos en la versión hebrea del Antiguo Testamento, es decir los libros que forman parte del Canon bíblico. Véase, Amy-Jill Levine, "Apocrypha”, en The Eerdmans Bible Dictionary, ed. David Noel Freedman (Grand Rapids, MI: William B. Eerdmans Publishing Company, 2000). Aquí se usa el término para dar a entender que en la actualidad muchos cristianos creen que esta oración forma parte del canon bíblico o lo consideran así, aunque este no exista en la literatura bíblica. 
En mi aflicción a sus fuertes brazos vuelo,

Él es mi amigo que me colma de alegría,

Solo en Él encontrar refugio puedo,

Solo en Él halla solaz el alma mía. $^{5}$

Aunque este hermoso himno habla de la persona del Señor Jesús como tal, hoy muchos se han apartado de esa idea, para decir que lo que el mundo necesita es de personas como Jesús. Es decir, para muchos la frase $\mathrm{El}$ mundo necesita de Jesús, en realidad significa, El mundo necesita que tú seas un Jesús. Debido a este razonamiento, la misión del cristiano, ha pasado de predicar a Jesús y sus hechos, a personificar a Jesús e imitar sus hechos. Los estudiosos bíblicos que apoyan esta posición, encuentran apoyo bíblico, pues claramente el mismo Pablo así lo hacía, él dice: "Sed imitadores de mí, así como yo de Cristo" (1 Col 11:1). También él ordena "Sed, pues,

5 Citado en William Hendriksen, Comentario al Nuevo Testamento: Filipenses, 18 vols. (Grand Rapids, MI: Libros Desafío, 2006), 88. imitadores de Dios como hijos amados. Y andad en amor, como también Cristo nos amó, y se entregó a sí mismo por nosotros..." (Ef 5.1-2), además el mismo Señor Jesús dijo: "Porque ejemplo os he dado, para que como yo os he hecho, vosotros también hagáis" (Jn 13:15).

Toda lo mencionado unido a la idea de que fue el mismo Señor Jesús quien, de forma clara y explicita, declaró cuál era su misión, cuando citando al profeta Isaías, dijo,

El Espiritu del Señor está sobre mi. Por cuanto me ha ungido para dar buenas nuevas a los pobres; me ha enviado a sanar a los quebrantados de corazón; a pregonar libertad a los cautivos,y vista a los ciegos. A poner en libertad a los oprimidos, a predicar el año agradable del Señor. Y enrollando el libro, lo dio al ministro, y se sentó; y los ojos de todos en la sinagoga estaban fijos en él. Y comenzó a decirles: Hoy se ha cumplido esta Escritura delante de vosotros. (Lc 4:18-21)6

6 A menos que se indique algo diferente, en este trabajo las citas bíblicas han 
Ha dado lugar a que algunos teólogos lleguen a la conclusión de que la misión del cristiano es vivir como un revolucionario, luchando por las clases sociales más desfavorecidas, trayendo justicia e igualdad a este mundo de desigualdad. Sin embargo, antes de analizar la misión del cristiano propuesto por la Teología de la Liberación, es necesario que se piense en lo que ocurriría si alguien viviría de tal forma que llegue a ser un Jesús en este mundo. Es decir, el mundo aceptaría a esta persona y la valoraría como el ejemplo a seguir, ¿sería él o ella visto como una solución a los problemas del mundo? En otras palabras, la pregunta es ¿Qué pasaría si uno a uno los seres humanos van convirtiéndose en una especie de Jesús moderno?

Responder esta pregunta no es muy difícil, pues para hacerlo, solo es necesario conocer bien lo que Jesús hizo y lo que, como consecuencia, le pasó. Sin embargo, conocer lo que él hizo y saber lo que le pasó, ya no es

sido tomadas de la Versión Reina Valera Revisada 1960, (Miami: Sociedades Bíblicas Unidas, 1998). En adelante RVA. tan sencillo, esto requiere mucho tiempo, puede tratarse de una tarea que lleve toda la vida. No obstante, se puede afirmar que si alguien se convierte en Jesús, le ocurriría lo mismo que le pasó al Jesús histórico de hace dos milenios.

\section{Libertad a los oprimidos}

Tratar de hablar de todas las acciones del Señor Jesús sería imposible, sus propios apóstoles dijeron "hay también otras muchas cosas que hizo Jesús, las cuales si se escribieran una por una, pienso que ni aun en el mundo cabrían los libros que se habrían de escribir" (Jn 21:25).

Sin embargo, alguien podría pensar que todas las obras del Señor Jesús se encuentran resumidas en el texto de Lucas 4:18-21, y haciendo una lectura literal y social del texto, se podría afirmar que la misión de Cristo es aquella propuesta por la Teología de la Liberación, ${ }^{7}$ y

7 La Teología de la Liberación, es un movimiento cristiano [realmente es más parecido a un movimiento político], que surgió en América Latina. El término fue 
ya que para este grupo la misión del cristiano es ser un Cristo viviente, se podría concluir diciendo que la misión del cristiano y la de su Señor resultan siendo la misma. Aunque esto podría ser motivo de otro estudio, es importante señalar que existen grandes diferencias entre la misión del cristiano y la del Señor Jesús. ${ }^{8}$

acuñado en 1971 por el sacerdote peruano Gustavo Gutiérrez, quien escribió uno de los libros más famosos del movimiento, Teología de la liberación (A Theology of Liberation). Veáse, Gustavo Gutiérrez, A Theology of Liberation: History Politics and Salvation (15th anniversary edition with a new introduction by the author) (Maryknoll: Orbis Press, 1988); James H. Harris, Preaching Liberation (Minneapolis, MN: Fortress Press, 1995), 11, 39-45.

8 Esta afirmación no contradice lo afirmado por Elena G. de White, pues esta no es la única cita en la que ella trata el tema de la misión del cristiano y la misión del Señor Jesús. Ella dice: "Somos un 'espectáculo al mundo, a los ángeles y a los hombres'. 1 Corintios 4:9. Nuestra misión es la misma que fue anunciada por Cristo al comienzo de su ministerio". Elena G. de White, Testimonios para la iglesia (Bogotá: Asociacion Publicadora Interamericana, 1955), 8:146. White también habla abundantemente sobre la muerte sustitutoria como siendo la misión del Señor Jesús, además señala que: "Aun sus amados discípulos, absortos en sus propias dudas, tris-
Sin embargo, estos argumentos referentes a la misión del Señor Jesús, hacen surgir una nueva interrogante, la pregunta es iEl Señor Jesús cumplió su misión cuando vino a este mundo?

Pues si su misión se resume en: 1) dar buenas nuevas a los pobres, 2) sanar a los quebrantados de corazón, 3) pregonar libertad a los cautivos, 4) dar vista a los ciegos, 5) libertar a los oprimidos y 6) predicar el año agradable del Señor, ipodría el cristianismo actual decir que Él tuvo éxito en el cumplimiento de su misión? Quien escribe el presente artículo, cree que el Señor Jesús tuvo completo éxito en el cumplimiento de su misión, sin embargo, se debe afirmar que si se lee estos pasajes de forma literal, a la luz de los conocimientos médicos, políticos y sociales del tiempo del Señor Jesús y de nuestros tiempos, se tendría que afirmar que su venida fue todo un fracaso.

Tanto en el tiempo del Señor

tezas y esperanzas ambiciosas, no habían comprendido el propósito de su misión". Elena G. de White, El deseado de todas las gentes (Bogotá: Asociacion Publicadora Interamericana, 1955), 391. 
Jesús, como en el nuestro, los pobres, los quebrantados, los cautivos, los ciegos y los oprimidos, entre otros, existieron y no dejaron de existir gracias a la primera venida del Señor Jesús. Él vivió, murió y resucito, luego se fue a los cielos y aparentemente las condiciones aquí descritas, continuaron iguales ${ }^{9}$ aun en el lugar dónde Él nació y desarrollo su ministerio. Acaso frente al fracaso en el cumplimiento de su misión, Él tuvo que agenciarse de un grupo de discípulos, para que hagan lo que Él no pudo hacer.

Aunque lo mencionado no parezca un argumento biblico, ello nos permite decir que, la misión del Señor Jesús, no está centrada en la liberación temporal,

9 Alguien podría decir, que Él solo inició el cambio, pues esa era su misión y que por esa razón Él necesita de sus discípulos, para completar aquello que empezó, la transformación de la raza humana a su imagen y semejanza, pero aunque esto pueda tener mucho sentido, no es eso lo que dice el texto, pues este afirma que, todo lo mencionado se estaba cumpliendo gracias a la llegada del Señor Jesús. Véase, Robert H. Stein, Luke, ed. David S. Dockery, 39 vols., The New American Commentary, vol. 24 (Nashville: Broadman \& Holman Publishers, 1992), 157. física y mundana del ser humano. Por lo tanto, la misión del cristiano no es una que esté relacionada con la propuesta por la Teología de la Liberación, debido a ello es imposible aceptar y predicar que la liberación de la injusticia económica, política o social -es decir ayudar a que las personas sean más felices y se encuentren en una situación más confortable desde un punto de vista humano-, sea la misión del cristiano, porque esa no era la misión del Señor Jesús y porque la misión del Señor Jesús y la de sus seguidores no es la misma.

Sin embargo, se debe recordar que el nombre propio, Jesús

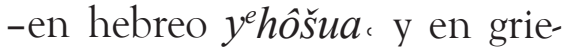
go Ièsous-, significa salvador, ${ }^{10}$ y que además Él es el Mesías māšiah - anunciado en el Antiguo Testamento, es decir el rey libertador, ${ }^{11}$ aquel que devuelve la paz y hace que esta perdure

10 Benjamin C. Chapman, "Jesus", en The Eerdmans Bible Dictionary, ed. David Noel Freedman (Grand Rapids, MI: William B. Eerdmans Publishing Company, 2000), 870.

11 The Seventh-day Adventist Bible Dictionary, s.v. "Messiah". 
por la eternidad. Todo lo mencionado, más los 117 nombres y títulos ${ }^{12}$ que se le da a este histórico y único personaje, no dejan duda respecto a su importancia para el mundo. Es decir, aunque hasta aquí se ha intentado mostrar que no siempre se comprende en qué consiste la misión del Señor Jesús, es necesario preguntarse: ¿Qué quiere decir la Biblia cuando afirma que Él es el libertador? Pues no se puede negar de que su nombre, sus palabras y el testimonio de sus discípulos, afirman que Él es el libertador.

\section{La necesidad del mundo}

Escribir sobre aquello que el mundo necesita, podría requerir miles de páginas pues, desde una perspectiva humanista, es el ser humano quien determina sus necesidades y el cómo satisfacerlas. Sin embargo, desde un punto de vista bíblico, la necesidad del mundo no es tan difícil de determinar. Algunos textos

12 H.L. Willmington, Willmington's Book of Bible Lists (Wheaton, IL: Tyndale, 1987), 160. que ilustran de forma directa o indirecta la necesidad del mundo dicen,

"Vi un cielo nuevo y una tierra nueva; porque el primer cielo y la primera tierra pasaron, y el mar ya no existía más. Y yo Juan vi la santa ciudad, la nueva Jerusalén, descender del cielo, de Dios, dispuesta como una esposa ataviada para su marido. Y oí una gran voz del cielo que decía: He aqui el tabernáculo de Dios con los hombres, y él morará con ellos; y ellos serán su pueblo, y Dios mismo estará con ellos como su Dios. Enjugará Dios toda lágrima de los ojos de ellos; y ya no habrá muerte, ni habrá más llanto, ni clamor, ni dolor; porque las primeras cosas pasaron" (Ap 21:1-4).13

"Pero el día del Señor vendrá como ladrón en la noche; en el cual los cielos pasarán con grande estruendo, y los elementos ardiendo serán deshechos, y la tierra y las obras que en ella

13 También se pueden leer ideas similares en los siguientes textos, Is 65:17; 66:22; 2 Pe 3:10, 13; Ap 20:11. 
hay serán quemadas. Puesto que todas estas cosas han de ser deshechas, icómo no debéis vosotros andar en santa y piadosa manera de vivir, esperando y apresurándoos para la venida del día de Dios, en el cual los cielos, encendiéndose, serán deshechos, y los elementos, siendo quemados, se fundirán! Pero nosotros esperamos, según sus promesas, cielos nuevos y tierra nueva, en los cuales mora la justicia" (2 Pe 3:10-13).

Estos versos, dicen de forma directa y clara que este mundo será destruido y que Dios hará otro planeta, los textos no dicen que Dios hará un arreglo del planeta actual, sino afirman que lo que se espera es un cielo nuevo y una tierra nueva, puesto que todas estas cosas -las del presente- han de ser deshechas.

Al parecer, la necesidad del mundo, no es la misma desde la perspectiva de Dios y del ser humano, pues mientras el ser humano cree que necesita reparar y hacer perdurar su planeta la mayor cantidad de tiempo posible, el Señor Jesús cree que este planeta debe ser destruido. También mientras el ser humano cree que este mundo necesita de paz, justicia, amistad y amor, el Señor Jesús afirma:

"Fuego vine a echar en la tierra... ¿Pensáis que he venido para dar paz en la tierra? Os digo: No, sino disensión. Porque de aqui en adelante, cinco en una familia estarán divididos, tres contra dos, y dos contra tres. Estará dividido el padre contra el hijo, y el hijo contra el padre; la madre contra la hija, y la hija contra la madre; la suegra contra su nuera, y la nuera contra su suegra" (Lc 12:49-53).

Aunque esta investigación no se propone estudiar cuál es la misión real de Cristo, leer este pasaje es importante para responder de forma satisfactoria la primera pregunta planteada: ¿El mundo necesita de Jesús? Martín al comentar este verso afirma que, "La misión de Jesús realmente terminó produciendo la clase de divisiones de que habló aquí. Las familias se han dividido y las lealtades se han roto. Los creyentes judíos toda- 
vía son excluidos de sus familias y amigos". ${ }^{14} \mathrm{Y}$ aunque muchos puedan pensar que lo que más necesita el mundo actual es paz y unidad, la realidad muestra que el Señor Jesús no solo dividió la historia en dos, sino que esta acción, como si se tratase de su misión, se prolongó aun a las personas y familias.

Frente a esta realidad, no queda otra cosa que preguntarse, ¿Qué es lo que el mundo realmente necesita? Podría ser que el mundo necesite no de una persona sino de una acción que solo esa única persona puede hacer. Frente a la pregunta ¿el mundo necesita de Jesús? No queda, duda de que la respuesta es SÍ, sin embargo, se debe reconocer que tanto la pregunta, como la respuesta no están bien planteadas y debido a ello, se produce una confusión en la mente del lector.

14 John F. Walvoord y Roy B. Zuck, eds., San Mateo, San Marcos, San Lucas, en El conocimiento bíblico, un comentario expositivo: Nuevo Testamento, vol. 1 (Puebla, México: Ediciones Las Américas, A.C., 1995), 313.
Por otro lado, hasta aquí se ha usado el término mundo para hacer referencia al planeta y a la humanidad en conjunto, lo que también produce confusión, por lo tanto, es necesario separar cada una de estas variables, y hacer preguntas separadas para brindar respuestas separadas, pues solo así se podrá encontrar sentido a las palabras y acciones del Señor Jesús. Se propone la siguiente secuencia de preguntas y respuestas.

¿El planeta tierra necesita de Jesús? Respuesta: Sí. ¿Para qué necesita el planeta tierra de Jesús? Respuesta: para que Él ponga punto final a su agonía, es decir, para que lo libere de su dolor, sufrimiento y devastación que sufre a consecuencia del pecado de la humanidad. Pues aunque aparentemente inerte, sin sentimientos y emociones, Dios afirma en su Palabra que "toda la creación gime a una, y a una está con dolores de parto hasta ahora" (Rm 8:22-23), texto que muy claramente hace referencia a todo el reino animal -dentro del cual los seres humanos no 
pueden ser considerados- ${ }^{15}$ vegetal y mineral.

¿La humanidad necesita de Jesús? Respuesta: Sí. ¿Para qué necesita la humanidad de Jesús? Respuesta: para que Él ponga punto final a las consecuencias de su pecado y del pecado, es decir, para que lo libere del pecado y sus consecuencias. Sin embargo, se debe reconocer que responder esta pregunta en una simple oración es imposible, pues aunque aparentemente ya se la haya respondido, la realidad es que todavía queda la interrogante, si el Señor Jesús no da solución rápida y en este momento a los problemas de falta de paz, desunión, injusticias y toda una serie de problemas sociales que hoy se viven, ¿para qué necesita la humanidad del Señor Jesús? El propio Señor Jesús expresó palabras -mientras estuvo en este planeta siendo parte de la hu-

15 El autor de esta investigación, cree que existe un reino que debería ser nombrado como el reino humano que, desde una perspectiva bíblica, no se debería considerar al ser humano dentro de la categoría del reino animal como lo hace el naturalismo evolucionista. manidad-, que pueden ayudar a encontrar una respuesta a esta importante pregunta, Él dijo:

"No se turbe vuestro corazón; creéis en Dios, creed también en mi. En la casa de mi Padre muchas moradas hay; si asi no fuera, yo os lo hubiera dicho; voy, pues, a preparar lugar para vosotros. Y si me fuere y os preparare lugar, vendré otra vez, y os tomaré a mi mismo, para que donde yo estoy, vosotros también estéis. Y sabéis a dónde voy, y sabéis el camino. Le dijo Tomás: Señor, no sabemos a dónde vas; ¿cómo, pues, podemos saber el camino? Jesús le dijo: Yo soy el camino, y la verdad, y la vida; nadie viene al Padre, sino por mí" (Jn 14:1-7).

Aunque el evangelio según San Juan registra siete oportunidades en las que el Señor Jesús usa la frase "Yo soy", aquí solo se enfocará una de ellas, la frase más significativa de esta porción bíblica, aquella que resume la idea principal, la idea central del pasaje, del enunciado del Señor Jesús. Él dijo: "yo soy el camino", esta es la idea 
principal, "la verdad y la vida"

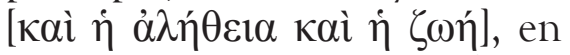
realidad son explicativos, ${ }^{16}$ que ayudan a entender la idea central. ${ }^{17}$ La idea que Él es el camino, es la idea en la que se debe centrar la atención, para responder a la pregunta, ¿Para qué necesita la humanidad del Señor Jesús?

\section{Yo soy el camino}

Él es el camino, en la mayoría de los lenguajes es posible hablar del Señor Jesús como un camino o una vía, en el sentido de que es una persona que facilita la llegada de otros a un destino en particular. Destino claramente señalado por el mismo Señor Jesús, pues Él dijo: "nadie viene al Padre, sino por mí", es decir, todos pueden ir al padre, pero por Jesús, dicho de otra manera,

16 Barclay Moon Newman y Eugene Albert Nida, A Handbook on the Gospel of John, UBS Handbook Series (New York: United Bible Societies, 1993), 457.

17 John Peter Lange, The Gospel According to John, ed. Philip Schaff, en A Commentary on the Holy Scriptures, vol. 3 (Bellingham, WA: Logos Bible Software, 2008), 437.
Jesús es el único por quien las personas van al padre.

Aunque, esta afirmación tiene una gran cantidad de implicancias, de todas ellas, solo una será abordada en este estudio. Aquella que dice que el Señor Jesús es el camino por el cual la humanidad puede ir al padre, idea que hoy en día muchos la verán como simbólica, pero que en su gran contexto bíblico, en realidad se trata de una idea literal, es decir, el Señor Jesús está hablando de un viaje literal a la presencia de Dios, un viaje en carne y cuerpo, un viaje en un tiempo determinado, un viaje que nos lleva al encuentro con el Padre, a la presencia de Dios a la mesa del cordero, al pie del trono de Dios. Apocalipsis, al hablar de este momento y de la humanidad que lo experimentará dice:

"Estos que están vestidos de ropas blancas, iquiénes son, y de dónde han venido? Yo le dije: Señor, tú lo sabes. Y Él me dijo: Estos son los que han salido de la gran tribulación, y han lavado sus ropas, y las han emblanquecido en la 
sangre del Cordero. Por esto están delante del trono de Dios, y le sirven día y noche en su templo; y el que está sentado sobre el trono extenderá su tabernáculo sobre ellos. Ya no tendrán hambre ni sed, y el sol no caerá más sobre ellos, ni calor alguno; porque el Cordero que está en medio del trono los pastoreará, y los guiará a fuentes de aguas de vida; y Dios enjugará toda lágrima de los ojos de ellos" (Ap 7:13-17).

Es decir, si alguien va al padre, va al cielo y si va al cielo, disfruta de un lugar y una vida en la que no existe dolor ni pecado ni nada de lo que aqueja a la humanidad presente. En otras palabras, existe la posibilidad de escapar de este mundo e ir a vivir en un paraíso, aquel que para muchos en la actualidad es solo una ilusión. Pero más importante aún, es recordar que este mundo gime y que pronto será destruido y consumido por fuego, que todo lo que esté y los que estén en él experimentarán la misma suerte, y que solo aquellos que hayan ido al cielo serán librados de la destrucción de este planeta y de su propia destrucción.
Por lo tanto, ante la pregunta: ¿Para que necesita la humanidad de Jesús?, la primera y única respuesta que será abordada en este estudio es: para que libere al ser humano de la inminente destrucción del planeta tierra, para que lleve al cielo a los liberados, y para que destruya a la humanidad que no esté preparada para vivir en el ambiente celestial. En pocas palabras, se podría decir que se necesita del Señor Jesús para escapar de la destrucción de este mundo.

Es decir, la humanidad necesita a Jesús, porque Él es el camino que permite escapar de la destrucción inminente. Él es el camino, no para transformar y mejorar el mundo, sino para ir a un mundo mejor, para viajar, a un lugar mejor. Es muy importante que las personas conozcan a Jesús y si es posible que ellos vean un reflejo del Señor Jesús a tráves de sus seguidores. Pero es más importante que ellos lo escuchen. Porque cuando Jesús no habla, la gente solo puede ver a una persona cariñosa, amable, compasiva y justa. Pero realmente no lo conocen. Debido a que 
no conocen su verdadera intención, por lo tanto, se puede afirmar que en verdad esa gente no conoce a Jesús, porque solo se puede conocer a otra persona cuando se habla con esa otra persona, es decir, cuando dos personas se relacionan entre sí y hablan entre si. Para entender mejor la importancia de esto, hay que recordar que el Señor Jesús dijo:

"No todo el que me dice: Señor, Señor, entrará en el reino de los cielos, sino el que hace la voluntad de mi Padre que está en los cielos. Muchos me dirán en aquel dia: Señor, Señor, ino profetizamos en tu nombre, y en tu nombre echamos fuera demonios, y en tu nombre hicimos muchos milagros? Y entonces les declararé: Nunca os conoci; apartaos de mi, hacedores de maldad" (Mt 7:21-23).

Por esta razón, la respuesta a la pregunta. ¿La humanidad necesita de Jesús?, es SÍ. Pero la respuesta a la pregunta. ¿Por qué la humanidad necesita a Jesús?, es, porque Él es el ca- mino que nos permite escapar de la destrucción venidera. Sin embargo, para responder a la pregunta. ¿Cómo Jesús nos ayuda a huir de la destrucción de este mundo?, es necesario usar más palabras. No obstante, se debe afirmar en base al texto anterior, que el Señor Jesús solo puede ayudar a escapar de la destrucción de este mundo, a quienes Él conoce. Y aunque es más fácil que yo lo conozca a Él, es necesario que Él me conozca, para que yo pueda ser salvado por Él. Pero para que Él llegue a conocerme, es necesario que Él me hable. Pues aunque el Señor Jesús es Dios, Él llega a conocer a un ser humano, de igual forma como un ser humano conoce a otro, por el diálogo mutuo y no por un permanente monólogo.

Es decir, que yo hable con el Señor Jesús, no garantiza que Él me conozca, pues esto estará garantizado solo si Él habla y yo también. Finalmente, debemos afirmar que todo esto nos 1leva a concluir afirmando que el ser humano no es salvo única- 
mente por conocer a Jesús, sino porque Jesús también lo conoce a él. Es decir, la liberación, la salvación de la destrucción inminente de la humanidad pecaminosa y del planeta, solo puede ser garantizada por un mutuo conocimiento entre el ser humano y el Señor Jesús.

\section{Conclusión: La verdadera misión del cristiano}

En base a todo lo señalado, se puede afirmar que la verdadera misión del cristiano, no tiene que ver con la representación del Señor Jesús ante el mundo, pues hacerlo solo permite que otros conozcan a Jesús, pero no da lugar a que Jesús los conozca a ellos. Es decir, todo trabajo misionero, social o de cualquier índole que el cristiano hace, debe ser solo un pretexto para presentar a Jesús ante otros, pero cuando se alcanza este primer objetivo, se debe estar consciente de que esto todavía no es suficiente para decir, ya cumplí con mi misión, ya que la verda- dera misión del cristiano debe ir un paso más allá, debe permitir que el Señor Jesús también conozca a las personas, es decir, que Él entable una relación en la que el dialogo sea de ida y vuelta y no en una sola dirección.

Este es el gran desafío que representa el cumplir la $\mathrm{mi-}$ sión. Trabajar para resolver problemas temporales es fácil, pero conseguir que la gente escuche a Jesús en este mundo ruidoso, es muy difícil, pero no imposible, sobre todo para personas inteligentes y deseosas de cumplir la verdadera misión del discípulo del Señor. Y aunque no es el propósito de este artículo hablar del ¿cómo Jesús habla con el ser humano?, o del ¿cómo cumplir esta misión eficientemente?, se debe cerrar este artículo afirmando, que Jesús solo habla a través de su Palabra escrita, y por esta razón, la misión cristiana es completa, solo si la gente lee la Biblia o si la Biblia es leída para ellos. 


\section{Bibliografía}

The Seventh-day Adventist Bible Dictionary. Editado por Siegfried H. Horn. Washington, DC: Review and Herald Publishing Association, 1979.

Chapman, Benjamin C. "Jesus". En The Eerdmans Bible Dictionary. Editado por David Noel Freedman. Grand Rapids, MI: William B. Eerdmans Publishing Company, 2000.

Greer, Clyde P. "Honestidad en el tratamiento de la historia". En Piense conforme a la Biblia. Editado por Richard Mayhue y John MacArthur. Grand Rapids, MI: Editorial Portavoz, 2005.

Gutiérrez, Gustavo. A Theology of Liberation: History Politics and Salvation (15th anniversary edition with a new introduction by the author). Maryknoll: Orbis Press, 1988.

Harris, James H. Preaching Liberation. Minneapolis, MN: Fortress Press, 1995.

Hendriksen, William. Comentario al Nuevo Testamento: Filipenses. 18 vols. Grand Rapids, MI: Libros Desafí, 2006.

Lange, John Peter. The Gospel According to John. Vol. 3. 63 vols. A Commentary on the Holy Scriptures, Editado por Philip Schaff. Bellingham, WA: Logos Bible Soft- ware, 2008.

Levine, Amy-Jill. "Apocrypha". En The Eerdmans Bible Dictionary. Editado por David Noel Freedman. Grand Rapids, MI: William B. Eerdmans Publishing Company, 2000.

Naranjo, Claudio. Cambiar la educación para cambiar el mundo. Providencia, Chile: Editorial Cuarto Propio Indigo, 2007.

Newman, Barclay Moon, y Eugene Albert Nida. A Handbook on the Gospel of John UBS Handbook Series. New York: United Bible Societies, 1993.

Samsam Valipur, Elias Natanael. El cristianismo bíblico. Maitland, FL: Xulon Press, 2006.

Stein, Robert H. Luke. Vol. 24. 39 vols. The New American Commentary, Editado por David S. Dockery. Nashville: Broadman Eु Holman Publishers, 1992.

Versión Reina Valera Revisada 1960. Miami: Sociedades Bíblicas Unidas, 1998.

Walvoord, John F., y Roy B. Zuck, eds. San Mateo, San Marcos, San Lucas. Vol. 1, El Conocimiento Bíblico Un Comentario Expositivo: Nuevo Testamento. Puebla, México: Ediciones Las Américas, A.C., 1995.

White, Elena G. de. El deseado de todas las gentes. Bogotá: Asociacion Publicadora Interamericana, 1955.

Testimonios para la iglesia. Vol. 8. Bogotá: Asociacion Publicadora Interamericana, 1955.

Willmington, H.L. Willmington's Book of Bible Lists. Wheaton, IL: Tyndale, 1987. 